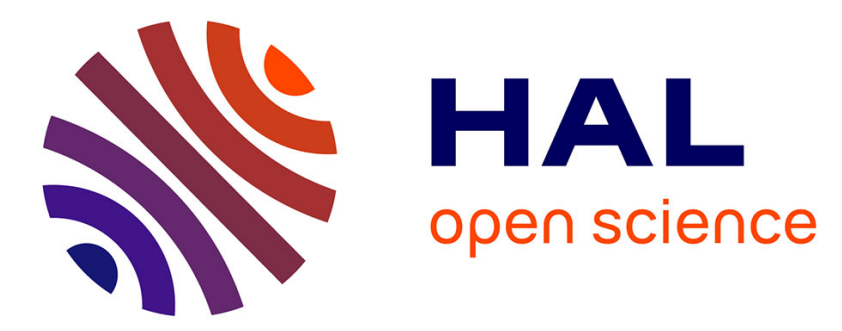

\title{
Interleaved multi-band pyramidal antennas combining radio navigation and telemetry satellite applications
}

Nelson Fonseca, Cyril Mangenot, Sami Hebib, Hervé Aubert, Olivier Pascal

\section{To cite this version:}

Nelson Fonseca, Cyril Mangenot, Sami Hebib, Hervé Aubert, Olivier Pascal. Interleaved multi-band pyramidal antennas combining radio navigation and telemetry satellite applications. Antennas and Propagation Society International Symposium, 2009, IEEE, Jun 2009, Charleston, United States. pp. 1-4, 10.1109/APS.2009.5171994 . hal-00432245

\section{HAL Id: hal-00432245 \\ https://hal.science/hal-00432245}

Submitted on 15 Nov 2009

HAL is a multi-disciplinary open access archive for the deposit and dissemination of scientific research documents, whether they are published or not. The documents may come from teaching and research institutions in France or abroad, or from public or private research centers.
L'archive ouverte pluridisciplinaire HAL, est destinée au dépôt et à la diffusion de documents scientifiques de niveau recherche, publiés ou non, émanant des établissements d'enseignement et de recherche français ou étrangers, des laboratoires publics ou privés. 


\title{
Interleaved Multi-band Pyramidal Antennas Combining Radio Navigation and Telemetry Satellite Applications
}

\author{
Nelson J.G. Fonseca* ${ }^{(1)}$, Cyril Mangenot ${ }^{(2)}$, Sami Hebib ${ }^{(3,4,5,6)}$, \\ Hervé Aubert $^{(3,6)}$, and Olivier Pascal ${ }^{(4,5)}$ \\ (1) CNES, 18 av. Edouard Belin, 31401 Toulouse, France \\ (2) ESTEC - ESA, Noordwijk, The Netherlands \\ (3) LAAS - CNRS, 7 av. Colonel Roche, 31077 Toulouse, France
}

(4) Université de Toulouse ; UPS, INPT ; LAPLACE (Laboratoire Plasma et Conversion d'Energie); 118 route de Narbonne, F-31062 Toulouse cedex 9, France

(5) CNRS ; LAPLACE ; F-31062 Toulouse, France

(6) INPT - ENSEEIHT, 2 rue Charles Camichel, 31071 Toulouse, France

E-mail: nelson.fonseca@cnes.fr

\section{Introduction}

Multi-band antennas combining several applications are of great interest as they enable to reduce the space needed for the aerials. This is even more important for on board satellite applications as the space to accommodate the antennas is limited. Some of the authors have introduced recently a new multi-band pyramidal antenna that combines radio navigation and telemetry applications [13]. The multi-band behavior of the antenna is achieved using traps that enable to adapt the length of the radiating element to the multiple operating frequencies. These traps limit in some way the available bandwidth at higher resonant frequencies. Also, if two different polarizations are required for the two combined applications (radio navigation requires right hand circular polarization, but telemetry may require right or left hand circular polarization depending on the mission), some difficulties in the design may appear at feeding network level.

To overcome these limitations, one of the authors suggested to separate the applications but to interleave the antennas in order to keep the same overall size for the antenna. In this communication, we validate this idea and compare the achieved performances with previous multi-band design. As expected bandwidth is improved for the telemetry application and interestingly coupling effects appear to have negligible impact on both input matching and radiation patterns.

\section{Antenna Description}

The proposed original antenna is constituted of 4 inclined radiating elements with traps to achieve a resonant monopole behavior at each operating frequency. To improve input matching, some of the authors proposed to make a hole in the ground plane and continue this hole by an under cut-off cylindrical waveguide to keep reasonable rear radiation level [1-3]. More recently, it was demonstrated that this cylindrical waveguide may be advantageously replaced by a conical 
waveguide [4]. The resulting antenna has a reduced height while keeping similar performances for both input matching and radiation patterns.

Each radiating element is a $1 \mathrm{~mm}$ wide metallic strip printed on a thin $(762 \mu \mathrm{m})$ low permittivity substrate (2.08). The length of the radiating element is defined by the lower operating frequency. The pyramidal shape of the antenna is achieved disposing the radiating elements upon a supporting structure transparent in radio frequencies (foam or polystyrene). The radiating elements disposal is particularly interesting as the polarization depends only on the feeding network: feeding all the elements with same amplitude and a phase progression of + or $-90^{\circ}$ will produce a right or left hand circular polarization, while feeding only two opposite elements with same amplitude and $180^{\circ}$ phase shift enables linear polarization. To keep this flexibility on the polarization, one may use diplexers between the radiating elements and the feeding network to separate the two combined applications [3]. This increases the complexity of the feeding network design and induces extra insertion losses. We investigate in this paper the possibility to interleave two pyramidal antennas with a $45^{\circ}$ rotation to separate the two combined applications. The concept is illustrated in fig. 1a, and compared to the previous design reported in fig. $1 \mathrm{~b}$. Interestingly, this improvement of the multiband antenna does not affect the overall antenna size and the two applications are naturally separated making it easier to design the respective feeding networks. It also reduces the number of traps needed.

\section{Simulation Results and Discussion}

The proposed idea is investigated in terms of electromagnetic performances through the analysis of an antenna combining radio navigation and telemetry applications. The reference antenna was already optimized in [4] to produce the following frequency plan:

- $\quad \mathrm{E} 5 \mathrm{a} / \mathrm{E} 5 \mathrm{~b}: 50 \mathrm{MHz}$ bandwidth centered at $1.197 \mathrm{GHz}$

- L1: $24 \mathrm{MHz}$ bandwidth centered at $1.575 \mathrm{GHz}$

- MicroSAT Telemetry: $90 \mathrm{MHz}$ centered at $2.245 \mathrm{GHz}$

To achieve the tri-band operation, two traps are needed per radiating element. The interleaved antenna design results in the combination of a mono and a bi-band antenna. Only one trap is now needed per radiating element on the bi-band antenna. Electromagnetic simulations were performed using the commercial tool CST Microwave Studio, which proved good correlation between simulation and measurements on the reference antenna with cut-off cylindrical waveguide [2, 3]. The input matching performances of the proposed antenna are presented in fig. 2. The upper navigation and the telemetry bands are clearly affected by the trap separating them. As mentioned in [2], the traps on the reference antenna limit the bandwidth for higher frequencies. One may note also that the resonant frequencies are slightly shifted in simulation: this is to anticipate the difference between the theoretical and the real electrical characteristics of the traps [3, 5]. For a VSWR better than 2 in simulations, the three bandwidths are respectively 47.8, 26.1 and $78.8 \mathrm{MHz}$ for the reference antenna. With the interleaved antennas design, the 
bandwidths are respectively $60.3,45.6$ and $214.9 \mathrm{MHz}$. As expected, the proposed design significantly increases the operating bandwidths, giving some margins to take into account any frequency shift due to the traps. This new design can also handle the whole telemetry bandwidth (which was not the case of previous design), thus enabling for a more generic design. Impact on radiation patterns was also investigated and performances are reported in fig. 3 . We clearly note that the presence of the telemetry antenna has no impact on the navigation patterns. The other way around, we note that the navigation antenna has a slight impact on the telemetry patterns. More precisely, the maximum directivity decreases of about $1.2 \mathrm{~dB}$ while the cross-polarization level increases of $1 \mathrm{~dB}$. Depending on the application, this slight degradation on the antenna performances may be acceptable. It is also to be balanced with the losses that would have been induced by the diplexers and that may be roughly of the same order for a design with offthe-shelf components. Interestingly, the coupling effect on the radiation patterns is independent of the polarization due to the very specific antenna geometry since the antenna can work on either left or right circular polarization without changing the radiating part. As a consequence similar patterns are achieved for both right and left handed circular polarization. We may also mention that this interleaved antennas design gives further optimization parameters to better fit the antenna performances to the specifications. For instance, one may set a different inclination angle for the two antennas. Also, if further bandwidth is needed for the mono-band antenna, one can replace the radiating wires by bow-ties, diamonds, etc.

\section{Conclusion}

We have proposed and validated through simulations the possibility to interleave two pyramidal multi-band antennas. This new design enables to overcome bandwidth limitation problems as only one trap is now needed per radiating element on the radio navigation antenna. The feeding network is simplified as the two applications are now separated and polarizations can be defined independently for the two applications without significant impact on antenna design.

\section{References}

[1] N.J.G. Fonseca, L. Ries, S. Hebib, H. Aubert and O. Pascal, “Antenna Having Oblique Radiating Elements", International Publication WO2008/125662 A1, October $23^{\text {rd }}, 2008$.

[2] S. Hebib, H. Aubert, O. Pascal, N.J.G. Fonseca, L. Ries and J.M.E. Lopez, "Multi-band and Circularly polarized Pyramidal Antenna Loaded by a Cut-off Waveguide", to be published in IEEE Trans. on Antennas and Propagation.

[3] S. Hebib, "Nouvelle Topologie d'Antennes Multi-bandes pour Applications Spatiales", PhD Thesis, Université de Toulouse, France.

[4] B. Palacin, N.J.G. Fonseca, S. Hebib and H. Aubert, "Investigations on the Shape of the Ground Plane of a Multi-band Antenna for 
GPS/Galiléo/Telemetry Applications", submitted to $16^{\text {th }}$ JNM Conference, May 27-29, 2009, Grenoble, France.

[5] S. Hebib, H. Aubert, O. Pascal, N.J.G. Fonseca, L. Ries and J.M.E. Lopez, "Trap-Loaded Pyramidal Tri-Band Antenna for Satellite Applications", IEEE AP-S Int. Symposium, July 5-12, 2008, San Diego, CA, USA.

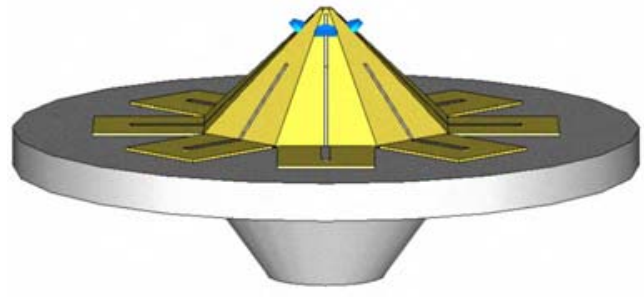

(a)

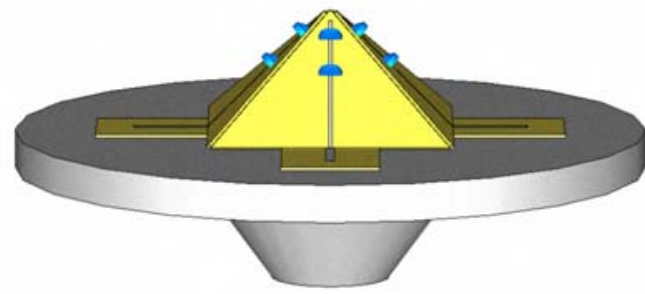

(b)

Fig. 1: (a) Proposed interleaved antennas and (b) reference multi-band antenna

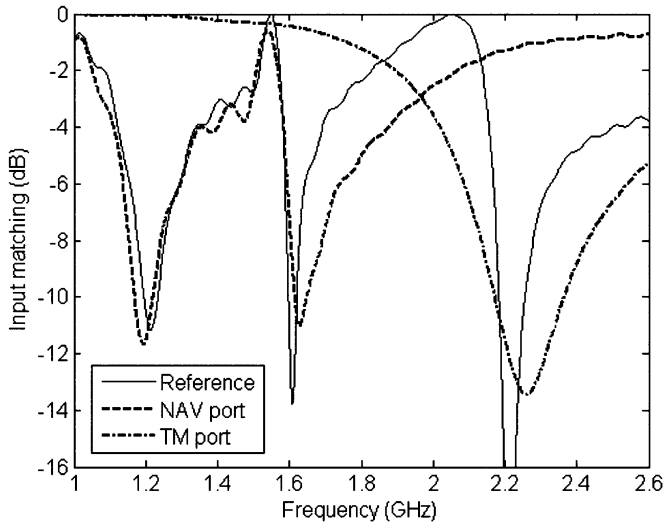

Fig. 2: Input matching

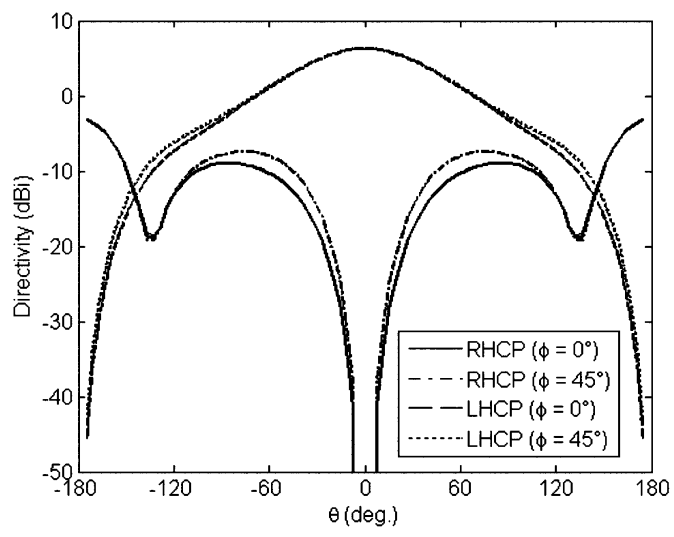

(b)

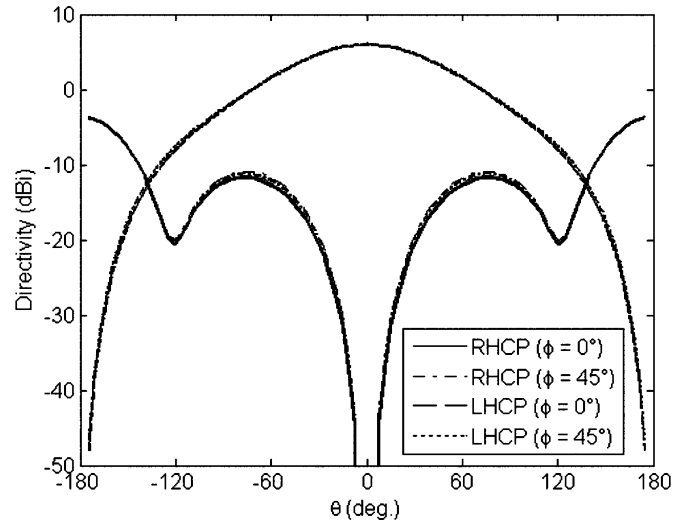

(a)

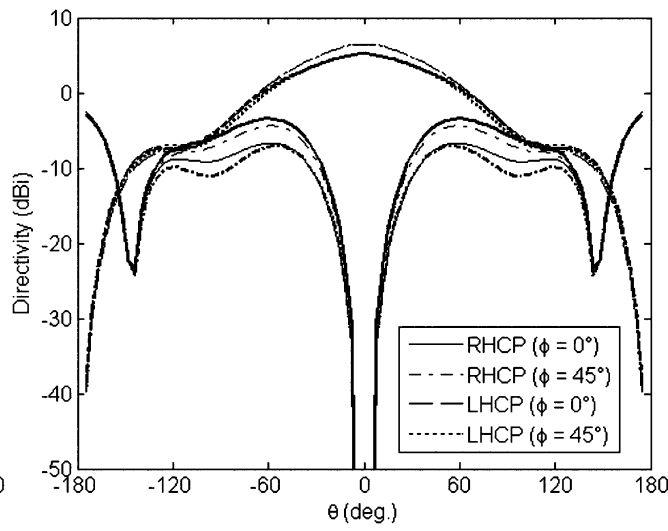

(c)

Fig. 3: Radiation patterns at (a) 1220MHz, (b) 1610MHz and (c) 2210MHz. (bold: interleaved antennas; thin: reference antenna) 